\section{REACTIVITY AND STRUCTURE OF MOLECULES}

$\mathrm{A}^{\mathrm{N}}$

N International Colloquium on Isotope Exchange and Molecular Structure was held in Paris during April 5-12 under the presidency of Mme. Joliot-Curie. It had been organised, with the support of the Rockefeller Foundation, by three French scientific workers well known for their contributions to these subjects, R. Daudel, M. Haïssinsky and P. Süe. About a dozen speakers had been asked to read papers; others had been invited to contribute to the discussions. A somewhat unusual feature was the friendly insistence by the organisers on French as the only 'official' language; but as the Paris colleagues had taken the trouble of translating papers before the congress started, all foreign authors bravely presented them in the language of their hosts. During the discussions most of them preferred to express, or to hear, the arguments in their mother tongue; this caused no difficulty, as good linguists were always present and willing to act as interpreters. (One of the most competent translators sometimes even quietly amplified what had actually been said by a speaker.) A further help was the distribution of the manuscripts in their original tongue to all the participants.

The discussions were lively and inspiring; they will be printed in full, together with the addresses, in Le Journal de Chimie et Physique. We shall confine ourselves here to a brief summary of the papers.

Although the main subject of the colloquium was the connexion between the structure of a molecule and its ability to take part in isotopic exchange processes, several of the papers dealt only with questions either of structure, or of exchange, leaving the conclusions to be drawn to the discussion or to further investigations. A contribution to the subject in its strict sense was the opening address by Prof. L. Pauling (Pasadena) on "Structure of Complexes and the Influence of Structure on Exchange Reactions" ; according to his calculations, the replacement of one group in a complex molecule by another may occur readily if the co-ordination number of the complex is smaller than the maximum permitted by steric considerations. To the same group belonged the papers by $P$. Süe and G. Kayas (Paris) on "The Behaviour of some perfect Cobalt Complexes in Szilard-Chalmers Reactions"; by B. Pullman, P. Rumpf and F. Kieffer (Paris) on "Isotopic Exchange Reactions and Electronic Structure of Substituted Aromatic Hydrocarbons"; and by C. K. Ingold (London) on "Isotope Exchange and the Mechanism of Heterolytic Substitution". A theoretical paper on "Free Valence in Organic Reactions" was read by Prof. C. A. Coulson (London).

Prof. C. D. Coryell (Boston, Mass.) discussed the results of studies carried out in the Clinton Laboratories on the valency states of the elements selenium, tellurium, bromine, iodine and cerium, if produced. by nuclear transformations and present only in tracer concentrations; he pointed out that the results are not yet numerous enough to offer themselves for broad generalizations. It is likely that each element will show poculiarities which can only be explored by detailed studies. An example of such an investigation of a single case was given by $P$. Süe in his work on the ions formed in sodium arsenite, sodium arsenate and sodium cacodylate under the impact of neutrons; it seems that in these reactions the lower valency state is favoured.
M. and Mme. Daudel, in collaboration with S. May, R. Muxart and O. Chalvet (Paris), presented a paper on "The chemical reactions which are the consequences of those nuclear reactions which do not change the nature of the element". Such a nuclear reaction may consist either in the absorption of neutrons with emission of $\gamma$-rays, or in a nuclear isomerization ; in the first case the observed chemical reactions are easy to foresee as following from the production of free, fast-moving atoms ; the chemical effects of isomeric nuclear changes have to be interpreted by a mechanism involving the re-arrangement of the electrons in the atom concerned. E. Broda (Vienna) discussed the various methods available for the determination of the yield of nuclear reactions of the $(\alpha, n)$ type ; he showed that the Szilard-Chalmers effect of the emitted neutrons offers certain advantages over the alternative methods of the ionization chamber or photographic plate. In a second paper he discussed the phenomenon of 'retention' of activity in cases where one would expect the Szilard Chalmers effect to give complete separation of the active atoms.

Two of the contributors dealt with heterogeneous exchange reactions. M. Haissinsky (Paris) deseribed experimental investigations carried out, together with M. Cottin and B. Varjadebian, on exchange between metal electrodes and their ions in solutions. Their object was to compare the exchange rates with the electrochemical potentials of the metals, taking into account also the possible effect of temperature, concentration, acidity, mechanical state of the surface, and all the other factors which may be of influence on exchange rates. The authors consider the imposing experimental material they have collected only as the beginning of further researches necessary for the full understanding of the exchange mechanism. In a second paper, M. Haissinsky examined in a critical way the possible connexions between the exchange processes on the surface of the electrode and various electrochemical phenomena; he found that his experiments support Piontelli's distinction of two classes of metals. The other paper on heterogeneous exchange was read by F. A. Paneth (Durham). The exchange of ions between solution and crystal surfaces has, since 1923 , often been used as a method for the determination of the extent of the surface area. In reviewing published and a few unpublished experiments, he has come to the conclusion that the exchanging part of the surface may be much smaller than the geometrical surface, but at the same time the only important one for the phenomena of adsorption and catalysis, and therefore well worth studying. This view was supported by Prof. M. Prettre (Lyon) Furthermore, the measurement of the equilibrium between ions in crystal surfaces and non-isotopic ions in solution may help to an understanding of the precipitation reactions of tracer elements without isotopic carriers.

The unfortunate absence of the authors did not diminish the interest taken in the papers by C. C. Evans and S. Sugden (London) on "Exchange Reactions and Electrolytic Dissociation", and by M. D. Kamen, J. W. Kennedy and O. E. Myers (St, Louis) on "Kinetic Studies on Isotopic Exchange Reactions" (both read by M. Haïssinsky), but naturally restricted the possibilities of a discussion.

At the end of the last session, before the concluding words of Mme. Joliot-Curie, Prof. G. v. Hevesy (Stockholm) summed up the proceedings by giving a brief résumé of all the contributions. During a break in the meetings the guests were given the opportunity 
of visiting the Laboratoire de Physique Nucléaire under the guidance of its director, F. Joliot (who was also an occasional contributor to the discussions), and the French Government's Atomic Energy Establishment at Châtillon, where preparations are far advanced for the erection of a heavy water-uranium oxide plant, and an impressive array of counting equipment of all types is being produced. Châtillon is an old fort in the outer defence girdle of Paris, and the skill with which the dark subterranean rooms have been converted into modern laboratories deserves admiration.

The last day of the congress was free from lectures and offered good opportunities to continue some of the discussions in smaller circles before the final dispersal of the participants of a very successful international meeting.

F. A. Paneth

\section{FAUNA AND FLORA OF PALESTINE}

DALESTINE'S fast diminishing larger fauna is bound to suffer from the Jewish-Arab war; many species of great historic interest may be exterminated, and several, like the gazelle, the geographical races of which have not yet been fully worked out by the modern zoologists in the country, may be among them. Attention was directed to the serious reduction in the numbers of the larger mammals by modern 'hunters' in special surveys reported in the bulletins of the Jerusalem Naturalists' Club in 1946. The difficulty of human food supplies will be a serious threat to the remaining numbers of ibex already on the verge of extinction in the country; and the departure of the Palestine Police Force which alone enforced the British-made game lawsthese prohibited the shooting of ibex, eagles, vultures, kestrels, owls, etc., and imposed certain close seasons and preserved certain forests against goat-grazingwill leave unrestricted the activities of 'hunters' and others. The grazing of these reserves by Beduin goatherds will have a serious effect upon plant life, for the ubiquitous goat is one of the most serious destroyers of flora in the country and a contributory factor to the costly menace of soil erosion.

Bab el Wad, which has been the scene of many recent news reports of a battle on the Jaffa-Jerusalem road, is a pine forest planted by the British authorities, twenty-four kilometres below Jerusalem. It consists mainly of Pinus halepensis and a large summer flora including Varthemia, Centaurea cyanoides, Helichrysum sanguineum, Cistus vilosus, Acanthus syriacus and many Labiates (Bull. 25, Jer. Nat. Club, p. 4), while W. F. W. Harding and E. Hardy collected and photographed in the forest the interesting amaryllid, Pancratium parviflorum, and Narcissus Tazetta, the Palestine iris, and various Crocus, Cyclamen, etc. (J. Roy. Hort. Soc., 71, 3 ; 1946).

The bird-life of Palestine, like the mammals, may see the most immediate threat since the removal of law and order to the larger birds of prey; but the netting of quail, suppressed by the British authorities, will probably be resumed for food, together with the unrestricted shooting of the many wildfowl that visit Lake Huleh and the Jordan Valley. The nightjar is among the birds recorded at Bab el Wad in Hardy's 1946 "Handlist of the Birds of Palestine", and this work pointed out that the great bustard, the Egyptian goose and the Syrian ostrich are already extinct in the country, and the white stork, the lam. mergeier, the imperial eagle and the white-faced duck no longer nest there.
Among the more immediate threats to bird-life in the present emergency will be that to the nesting colony of purple herons at Lake Huleh, the young of which are eaten as food by the Arabs. Other scarce birds likely to be sought to augment the food supplies are the houbara or Macqueen's bustard of the southern and Jordan deserts, which no longer nests in the country, the red-billed chukor partridge of the central hills and the Hey's sand partridge of the semi-deserts. Quail-catching and the shooting of songbirds for food will probably assume the large extent they already reach in Syria. The Hebrew University has shown an active interest in plant and bird conservation, and they and the Arab Scout movement and several private individuals were active supporters of the efforts made by the now defunct Jerusalem Naturalists' Club to conserve the rapidly diminishing fauna of the Holy Land during the last few years of the British mandate, especially at Lake Huleh and in the Jordan Valley; but with the lifting of the central authority, it is to be feared that animal life will suffer from the extensive use of rifle and poison before law and order restore close seasons, game reserves and the control of fire-arms, which are essential if the large mammals like the leopard, ibex, wolf, cheetah and gazelle are to survive.

\section{AFFORESTATION AS A WORLD PROBLEM}

TN a brochure entitled "Forestry and Forest Products-World Situation 1937-1946", issued by the Food and Agriculture Organisation of the United Nations, a graphic exposition of the world's position was produced (see Nature, May 8, p. 710). Prof. H. G. Champion, professor of forestry, University of Oxford, also discussed this theme in a paper entitled "Afforestation as a World Problem" before the Royal Society of Arts on March 17 In this paper he discussed various aspects of forestry and forestry work. As he correctly says, "the majority of us pay little attention to the changes which have taken place in the past in the natural vegetation which covers most of the land not taken up by buildings, roads, gardens, mines or agricultural crops We are barely conscious of the fact that in Britain almost every acre of cultivation and bare land-except on the hill tops and in the fens-has been cleared from the forest which once covered nearly the whole surface. From being a country almost entirely under forest, England has now a lower proportion than any other country in Europe." How often did a predecessor of Prof. Champion's at Oxford, Sir William Schlich, point this out to a deaf Government ?

The respective positions of Western European countries, as shown by figures given by the Food and Agriculture Organisation, are contrasted. The interesting position of the Middle East, contrasted with its position in Biblical and Roman times, is discussed; also that of America, Central and South Africa and Australia. Here the picture is chiefly one of ruthless destruction of the forests, either in the interest of agriculture or stock raising, or due to the habits of the local and introduced populations of annual unchecked firing of the countryside for whatever purpose, and over-grazing. Such actions have produced serious conditions in temperate climates. In the tropics they are devastating. For example, Prof. Champion states that in Nigeria it has been 